\title{
Nanoparticles: Characterization, Biological Synthesis and Applications
}

\author{
EL-Ghwas DE ${ }^{1}$, Elkhateeb WA ${ }^{1 *}$, Akram $\mathrm{M}^{2}$ and Daba GM${ }^{1}$ \\ ${ }^{1}$ Chemistry of Natural and Microbial Products Department, National Research Centre, Egypt \\ ${ }^{2}$ Department of Eastern Medicine, Government College University Faisalabad, Pakistan
}

*Corresponding author: Waill A Elkhateeb, Chemistry of Natural and Microbial Products Department, Pharmaceutical Industries Division, National Research Centre, Dokki, Giza, 12622, Egypt, Tel: +201013241936; Fax: +20233370931; Email: waillahmed@yahoo.com

\section{Review Article}

Volume 6 Issue 2

Received Date: May 24, 2021

Published Date: June 23, 2021

DOI: $10.23880 /$ oajmb-16000196

\section{Abstract}

The development of eco-friendly technologies in material synthesis is of considerable importance to expand their biological applications. Nowadays, a variety of inorganic nanoparticles with well-defined chemical composition, size, and morphology have been synthesized by using different microorganisms. This paper highlights the recent developments of the biosynthesis of inorganic nanoparticles and provides an insight about microbial biosynthesis of nanomaterial by bacteria, yeast and moulds for the manufacturing of sensoristic devices, therapeutic/diagnostic, and industrial applications.

Keywords: Microbial Nanoparticles; Biological Synthesis; Plant; Fungi; Yeast; Bacteria

Abbreviations: SEM, TEM: Scanning and Transmission Electron Microscopy; FTIR: Fourier Transform Infrared Spectroscopy: XPS: X-Ray Photoelectron Spectroscopy; AFM: Atomic Force Microscopy; DLS: Dynamic Light Scattering; XRD: Powder X-Ray Diffractometry; SEM: Scanning Electron Microscope; TEM: Transmission Electron Microscope; SMPS: Scanning Mobility Particle Size; NMR: Nuclear Magnetic Resonance; DMA: Differential Mobility Analyser; CPC: Condensation Particle Counter; CNT: Carbon Nano Tubes

\section{Introduction}

Nanotechnology facilitates the development of technology that deals with manometer-sized objects [1]. Nanoparticles are the most important aspect of nanotechnology. Nanoparticles are made up of carbon, metal, metal oxides, or organic matter and range in size from 1 to 100 nanometres [2]. The use of nanomaterial in biotechnology brings biology and material science together.
Nanoparticles provide a fundamentally useful forum, demonstrating specific properties with a broad range of possible applications [3]. Due to the numerous advantages of biological systems over non-biological systems, some research groups have discouraged the use of biological systems for nanoparticle synthesis.

As compared to their counterparts at larger scales, nanoparticles have distinct physical, chemical, and biological properties. This is due to a greater surface area to volume ratio, increased reactivity or stability in a chemical phase, increased mechanical power, and other factors [4]. Nanoparticles' properties have contributed to their use in a variety of applications. Nanoparticles have unique properties and applications due to a number of factors, including their close size to biomolecules like proteins and polynucleic acids [5]. Apart from their material, nanoparticles come in a variety of dimensions, shapes, and sizes [6]. A nanoparticle can be zero dimensional, with the length, breadth, and height 


\section{Open Access Journal of Microbiology \& Biotechnology}

all set at a single point, such as nano dots, one dimensional, with just one parameter, such as grapheme, two dimensional, with length and breadth, such as carbon nanotubes, or three dimensional, with all three parameters, such as length, breadth, and height, such as gold nanoparticles, or three dimensional, with all three parameters.

Nanoparticles may also be circular, cylindrical, tubular, conical, hollow centre, spiral, smooth, or irregular in shape, with sizes ranging from $1 \mathrm{~nm}$ to $100 \mathrm{~nm}$. The soil, on the other hand, may be uniform or irregular, with surface variations. Some nanoparticles are crystalline or amorphous, with single or multi crystal solids that can be loose or clumped together [7].

Furthermore, a variety of synthesis methods are being produced or improved in order to improve properties and lower production costs. Some methods have been tweaked to improve the optical, mechanical, physical, and chemical properties of particular nanoparticles [5]. Physical, chemical, and biological methods are used to create nanoparticles [8]. Physical and chemical approaches are both prohibitively expensive [9]. The biological methods of nanoparticle synthesis would help to eliminate harsh processing conditions by allowing synthesis at physiological $\mathrm{pH}$, temperature, and pressure at a low cost. It also has strong polydispersity, proportions, and stability at the moment. A large number of microorganisms have been discovered to be capable of synthesising inorganic nanoparticle composites, both intracellular and extracellular. Nanoparticles have gained prominence in recent years in a variety of fields, including oil, health care, the climate, agriculture, and others, due to their improbable properties. In addition, nanoparticles are now used in a wide range of materials, including cooking vessels, electronics, renewable energy, and the aerospace industry. Nanotechnology holds the key to a future that is both safe and sustainable. In this review, we have discussed general approaches to the biological synthesis of nanoparticles, its characterization and applications.

\section{Characterization}

Nanoparticlecharacterizationis criticalforunderstanding and controlling nanoparticle synthesis and applications. Scanning and transmission electron microscopy (SEM, TEM), Fourier transform infrared spectroscopy (FTIR), X-ray photoelectron spectroscopy (XPS), atomic force microscopy (AFM), dynamic light scattering (DLS), powder X-ray diffractometry (XRD), and UV-Vis spectroscopy are some of the techniques used to characterise nanoparticles. Different parameters such as particle size, shape, crystallinity, fractal dimensions, pore size, and surface area can be resolved using these techniques. These techniques could also determine the orientation, intercalation, and dispersion of nanoparticles and nanotubes in nan composite materials. TEM, SEM, and AFM can be used to assess particle morphology and scale. The advantage of AFM over traditional microscopes like SEM and TEM is that it tests 3D images, allowing particle height and volume to be calculated. The size distribution of particles is also determined using dynamic light scattering. In addition, X-ray diffraction is used to determine crystallinity, and UVVis spectroscopy is used to validate sample formation by displaying the Plasmon resonance [10-18].

\section{Size}

One of the most basic and important measurements for nanoparticle characterisation is the particle size. It defines the particle's size and distribution, as well as whether it is on the nano or micro scale. Electron microscopy is the most common method for determining particle size and distribution. Particles and clusters are measured using Scanning Electron Microscope (SEM) and Transmission Electron Microscope (TEM) images, while bulk samples in solid phase are measured using laser diffraction methods [19]. Photon correlation spectroscopy and centrifugation are used to quantify the particles in the liquid phase. Since imaging techniques for particles in the gaseous phase are complicated and irreversible, a Scanning Mobility Particle Size (SMPS) is used, which offers faster and more precise measurements than other approaches.

\section{Surface Area}

In the identification of nanoparticles, the surface area is also essential. A nanoparticle's surface area to volume ratio has a major impact on its efficiency and properties. BET analysis is the most common method for determining the surface area. For the surface area analysis of particles in liquid phase, a simple titration is necessary, but it is a labour-intensive method. As a result, nuclear magnetic resonance (NMR) spectroscopy is used. The surface area of nanoparticles in the gaseous phase is measured using a modified SMPS and a differential mobility analyser (DMA).

\section{Composition}

The purity and efficiency of a nanoparticle are determined by its chemical or elemental composition. Higher levels of secondary or undesirable elements in a nanoparticle may reduce its efficiency and cause secondary reactions and contamination in the process. X-ray photoelectron spectroscopy (XPS) is commonly used to determine composition [20]. Some methods, such as mass spectrometry, atomic emission spectroscopy, and ion chromatography, include chemical digestion of the particles accompanied by wet chemical analysis. The particles in the gaseous phase are collected either by filtration or electrostatically, and 


\section{Open Access Journal of Microbiology \& Biotechnology}

the analysis is done using spectrometric or wet chemical techniques [21].

\section{Surface Morphology}

The shapes and surface structures of nanoparticles play an important role in exploiting their properties. Spherical, flat, cylindrical, tubular, conical, and irregular forms with crystalline or amorphous surfaces with uniform or irregularities on the surface are some of the shapes. Electron microscopy imaging techniques such as SEM and TEM are commonly used to assess the surface [22]. Particles in the liquid phase are deposited on a surface and analysed, while particles in the gaseous phase are captured electrostatically or by filtration for electron microscopy imaging.

\section{Surface Charge}

A nanoparticle's interactions with the target are determined by its surface charge, or charge. A zeta potentiometer is used to calculate surface charges and their dispersion stability in a solution in general [19]. The charge of nanoparticles in gaseous phase is determined using a Differential Mobility Analyser (DMA).

\section{Crystallography}

The study of the arrangement of atoms and molecules in crystal solids is known as crystallography. A powder X-ray, electron, or neutron diffraction method is used to determine the structural arrangement of nanoparticles [23].

\section{Concentration}

The amount of air or gas needed for the process is determined by measuring the concentration of nanoparticles in the gaseous phase. The performance or efficiency of a system is determined by the concentration, scale, and distribution of nanoparticles in a unit volume of air or gas. A Condensation Particle Counter is commonly used to calculate concentrations (CPC).

\section{Biological Synthesis of Nanoparticle}

Our key purpose is to highlight on the biological synthesis of nanoparticles, because of its easiness of rapid synthesis, controlled toxicity, controlling on size characteristics, reasonable, and eco-friendly approach. A sum of natural sources is there for nanoparticle synthesis, together with plants, fungi, yeast, bacteria, etc. Additionally, the unicellular and multicultural organisms are able to synthesise intracellular and extracellular inorganic nanoparticles. The various sources of nanoparticles synthesis are enlisted in Table 1.

\section{Nanoparticle Synthesis by Plant Extracts}

Make use of plants in the synthesis of nanoparticles has drawn more interest of workers because it provides single step biosynthesis process. Plants tender a superior option for synthesis of nanoparticle, as the protocols involving plant sources are free from toxicants; furthermore, natural capping agents are readily supplied by the plants. For example, the production of gold and silver nanoparticles using Geranium extract [24], Aloe vera plant extracts [25], sun dried Cinnamomum camphora and Azadiracta indica leaf extract has been explained [26]. Also, inexpensive reduction of silver and gold ions present concurrently in solution, during exposure to plant leaf extract, generates bimetallic silver and gold shell nanoparticles. The information is also available for the synthesis of silver nanoparticles, using Plumeria rubra plant latex [27]. Nanoparticle synthesis furthermore carried out using Szyygium aromaticum bud extract, Murraya koenigii leaf extract. This synthesis is owing to the natural reducing agent eugenol and could be carbazoles present in the extracts correspondingly $[28,29]$. On the other hand, biosynthesis of gold nanoparticles utilizing the leaf extract of Mirabilis jalapa was explicated [30].

\section{Nanoparticle Synthesis by Bacteria}

In previous years, synthesis of nanoparticles using bacteria has enlarged comprehensively due to its immense application. Bacillus species has depicted to synthesise metal nanoparticles, researchers showed the ability of bacteria to decrease silver and fabrication of extracellular, consistently circulated nanoparticles, ranging from 10-20 $\mathrm{nm}$ size [31]. The Silver producing bacteria isolated from the silver mines exhibit the silver nanoparticles accumulated in the periplasmic space of Pseudomonas stutzeri AG259 [32]. Bacteria are also used to synthesize gold nanoparticles. Sharma, et al. [33] reported that whole cells of a novel strain of Marinobacter Pelagius are applicable for stable, monodisperse gold nanoparticle formation. Prasad, et al. [34] has been reported use of Lactobacillus strains to synthesise the titanium nanoparticles. The understanding of natural processes will apparently help in the discovery of entirely new and unexplored methodology of metal nanoparticle synthesis.

\section{Nanoparticle Synthesis by Fungi}

Biological production of nanoparticles by fungi is determined nowadays because of their reception towards toxicity, higher bioaccumulation, comparatively economic, effortless synthesis method and simple downstream processing and biomass handling. Extracellular biosynthesis of silver nanoparticles by Aspergillus Niger [35], Fusarium solani [36] and Aspergillus oryzae are reported to produce 


\section{Open Access Journal of Microbiology \& Biotechnology}

silver nano crystals [37]. The Pleurotus sajor caju was also used for synthesis of nanoparticles extracellular [38]. The spherical nanoparticle can be synthesized by Trichoderma viride [39]. Prologue of silver ions to Fusarium oxysporum leads to synthesis of stable Ag hydrosols [40]. Phoma glomerata has been traced to produce silver nanoparticles, and its efficiency against E. coli, S. aureus and P. aeruginosa has been assessed [41]. The genus Penicillium seems to have a superior contender for the silver nanoparticle synthesis, where production proceeds via extracellular mechanism [42].

\section{Nanoparticle Synthesis by Yeast}

The extracellular synthesis of nanoparticles in huge quantities, with straightforward downstream processing, has been reported by Kowshik, et al. [43]. This group has been involved in isolation of silver tolerant yeast strain MKY3, by inoculating with aqueous silver nitrate. The formation of 2-5 $\mathrm{nm}$ silver nanoparticles takes place in the forced ecological conditions. The synthesis of cadmium nanoparticles by using Candida glabrata and Schizosaccharomyce pombe has been reported by Dameron, et al. [44]. The silver and gold nanoparticles biosynthesis were also investigated by Mourato, et al. [45], using an extremophilic yeast strain isolated from acid mine drainage. The marine yeast Rhodosporidium diobovatum has been explored for intracellular synthesis of stable lead sulphide nanoparticles [46].

\begin{tabular}{|c|c|c|}
\hline Source & Types and size of NPs (nm) & References \\
\hline \multicolumn{3}{|c|}{ Plant } \\
\hline Azadirachta indica & $\mathrm{Ag}, \mathrm{Au} 50 / 100$ & Shankar, et al. [24] \\
\hline Aloe vera & $\mathrm{Au} \mathrm{50/350}$ & Chandran, et al. [25] \\
\hline Cinnamomum camphora & $\operatorname{Ag} 50$ & Huang, et al. [26] \\
\hline Szygium aromaticum & $\mathrm{Ag}, \mathrm{Au}$ & Kalpana devi, et al. [47] \\
\hline Murraya koenigii & $\mathrm{Ag}$ & Christensen, et al. [29] \\
\hline Plumeria rubra & $\mathrm{Ag}$ & Patil, et al. [27] \\
\hline Citrus aurantium & $\mathrm{Ag}$ & Pala, et al. [48] \\
\hline Geranium leaf plant extract & $\operatorname{Ag} 16 / 40$ & Shankar, et al. [24] \\
\hline \multicolumn{3}{|c|}{ Bacteria } \\
\hline Bacillus cereus & $\operatorname{Ag} 5$ & Ganesh Babu and Gunasekaran [49] \\
\hline Bacillus thuringiensis & Ag $10 / 20$ & Jain, et al. [50] \\
\hline Escherichia coli & $\operatorname{Ag~30/50}$ & Gurunathan, et al. [51] \\
\hline Escherichia coli & Cds & Sweeney, et al. [52] \\
\hline Lactobacillus strains & $\mathrm{Ag}, \mathrm{Au} 15 / 40$ & Sintubin, et al. [53] \\
\hline Pseudomonas stutzeri & $\mathrm{Ag}>200$ & Klaus, et al. [54] \\
\hline Corynebacterium & Ag 5/15 & Zhang, et al. [55] \\
\hline Staphylococcus aureus & $\operatorname{Ag~150/180}$ & Nanda and Saravanan [56] \\
\hline \multicolumn{3}{|c|}{ Fungi } \\
\hline Aspergillus niger & $\operatorname{Ag} 20$ & Gade, et al. [35] \\
\hline Aspergillus oryzae & Ag 5-50 & Binupriya, et al. [36] \\
\hline Fusarium oxysporum & $\operatorname{Ag} 1 / 5$ & Duran, et al. [57] \\
\hline Fusarium solani & Ag 5/35 & Ingle, et al. [37] \\
\hline Pleurotus sajor-caju & $\operatorname{Ag~5/50}$ & Nithya and Ragunathan [58] \\
\hline Trichoderma viride & $\operatorname{Ag~} 10 / 40$ & Thakkar, et al. [39] \\
\hline Klebsiella pneumoniae & Se $100 / 400$ & Fesharaki, et al. [59] \\
\hline \multicolumn{3}{|c|}{ Yeast } \\
\hline Silver-tolerant strain $M K Y 3$ & $\operatorname{Ag} 2 / 20$ & Kowshik, et al. [60] \\
\hline Candida glabrata & CdS 50/150 & Dameron, et al. [44] \\
\hline Schizosaccharomyce pombe & CdS 50/150 & Dameron, et al. [44] \\
\hline Extremophillic yeast & $\mathrm{Ag}$ & Mourato, et al. [61] \\
\hline Rhodospiridium dibovatum & $\mathrm{PbS}$ & Seshadri, et al. [62] \\
\hline
\end{tabular}

Table 1: Some sources of nanoparticles synthesis. 


\section{Open Access Journal of Microbiology \& Biotechnology}

\section{Classification of Nanoparticles}

The nanoparticles are generally classified into the organic, inorganic and carbon based.

\section{Organic Nanoparticles}

Dendrimers, micelles, liposomes and ferritin, etc. are commonly knows the organic nanoparticles or polymers. These nanoparticles are biodegradable, non-toxic, and some particles such as micelles and liposomes have a hollow core, also known as nano capsules and are sensitive to thermal and electromagnetic radiation such as heat and light [63]. These unique characteristics make them an ideal choice for drug delivery. The drug carrying capacity, its stability and delivery systems, either entrapped drug or adsorbed drug system determines their field of applications and their efficiency apart from their normal characteristics such as the size, composition, surface morphology, etc. The organic nanoparticles are most widely used in the biomedical field for example drug delivery system as they are efficient and also can be injected on specific parts of the body that is also known as targeted drug delivery.

\section{Inorganic Nanoparticles}

Inorganic nanoparticles are particles that are not made up of carbon. Metal and metal oxide-based nanoparticles are generally categorised as inorganic nanoparticles.

\section{Metal}

Nanoparticles that are synthesised from metals to nonmetric sizes either by destructive or constructive methods are metal based nanoparticles. Almost all the metals can be synthesised into their nanoparticles [64]. The commonly used metals for nanoparticle synthesis are aluminium (Al), cadmium (Cd), cobalt (Co), copper $(\mathrm{Cu})$, gold $(\mathrm{Au})$, iron $(\mathrm{Fe})$, lead $(\mathrm{Pb})$, silver $(\mathrm{Ag})$ and zinc $(\mathrm{Zn})$. The nanoparticles have distinctive properties such sizes as low as 10 to $100 \mathrm{~nm}$, surface characteristics like high surface area to volume ratio, pore size, surface charge and surface charge density, crystalline and amorphous structures, shapes like spherical and cylindrical and colour, reactivity and sensitivity to environmental factors such as air, moisture, heat and sunlight etc.

\section{Metal Oxides}

The metal oxide-based nanoparticles are synthesised to modify the properties of their respective metal-based nanoparticles, for example nanoparticles of iron (Fe) instantly oxidises to iron oxide $\left(\mathrm{Fe}_{2} \mathrm{O}_{3}\right)$ in the presence of oxygen at room temperature that increases its reactivity compared to iron nanoparticles. Metal oxide nanoparticles are synthesised mainly due to their increased reactivity and efficiency [65]. The commonly synthesised are Aluminium oxide $\left(\mathrm{Al}_{2} \mathrm{O}_{3}\right)$, Cerium oxide $\left(\mathrm{CeO}_{2}\right)$, Iron oxide $\left(\mathrm{Fe}_{2} \mathrm{O}_{3}\right)$, Magnetite $\left(\mathrm{Fe}_{3} \mathrm{O}_{4}\right)$, Silicon dioxide $\left(\mathrm{SiO}_{2}\right)$, Titanium oxide $\left(\mathrm{TiO}_{2}\right)$, Zinc oxide $(\mathrm{ZnO})$. These nanoparticles have possessed an exceptional property when compared to their metal counterparts.

\section{Carbon Based}

The nanoparticles made completely of carbon are knows as carbon based [66]. They can be classified into fullerenes, graphene, carbon nano tubes (CNT), carbon nanofibers and carbon black and sometimes activated carbon in nano size.

Fullerenes: Fullerenes $\left(\mathrm{C}_{60}\right)$ is a carbon molecule that is spherical in shape and made up of carbon atoms held together by $\mathrm{sp}^{2}$ hybridization. About 28 to 1500 carbon atoms form the spherical structure with diameters up to $8.2 \mathrm{~nm}$ for a single layer and 4 to $36 \mathrm{~nm}$ for multi-layered fullerenes.

Graphene: Graphene is an allotrope of carbon. Graphene is a hexagonal network of honeycomb lattice made up of carbon atoms in a two-dimensional planar surface. Generally, the thickness of the graphene sheet is around $1 \mathrm{~nm}$.

Carbon Nano Tubes (CNT): Carbon Nano Tubes (CNT), a graphene nano foil with a honeycomb lattice of carbon atoms is wound into hollow cylinders to form nanotubes of diameters as low as $0.7 \mathrm{~nm}$ for a single layered and 100 $\mathrm{nm}$ for multi-layered CNT and length varying from a few micrometres to several millimetres. The ends can either be hollow or closed by a half fullerene molecule.

Carbon Nanofiber: The same graphene nano foils are used to produce carbon nanofiber as CNT but wound into a cone or cup shape instead of a regular cylindrical tube.

Carbon Black: An amorphous material made up of carbon, generally spherical in shape with diameters from 20 to 70 $\mathrm{nm}$. The interaction between the particles is so high that they bound in aggregates and around $500 \mathrm{~nm}$ agglomerates are formed.

\section{Application}

NPs are involved in various applications from different fields such as imaging, catalysis, energy based research, medical applications, and environmental applications. Thanks to the unique characteristics of NPs, and their role in increasing the drugs rat ability and convenient controlled 


\section{Open Access Journal of Microbiology \& Biotechnology}

drug release properties. Some of the important applications of NPs include:

\section{Pharmaceutical and Medicinal Applications}

Simple and complex nano-sized inorganic particles represent an important material in the field of novel nano devices development which can be applied in several biological, physical, pharmaceutical, and biomedical applications. Thanks to their unique chemical and physical properties, optical properties (in case of photo thermal therapeutic applications and biological and cell imaging applications), and their ability to deliver drugs in specific dosage which increase drug therapeutic efficiency, minimize side effects, and improve patient compliance [67-71]. The controlled release of drugs to the exact action site at the therapeutically optimum degree and dose regimen has been a major goal in designing such devices. However, improving hydrophilic NPs as drug carrier was representing a challenge, which was achieved through different approaches such as using polylactic acid and polyethylene oxide as promising for the drug intravenous administration system [70]. In the field of biomedical applications, iron oxide particles such as magnetite $\left(\mathrm{Fe}_{3} \mathrm{O}_{4}\right)$ or its oxidized form maghemite $\left(\mathrm{Fe}_{2} \mathrm{O}_{3}\right)$ represent the most commonly employed NP $[72,73]$. On the other hand, super paramagnetic iron oxide NPs with appropriate surface chemistry is involved in numerous in vivo applications such as tissue repair, MRI contrast enhancement, immunoassay, cell separation, biological fluids hyperthermia detoxification, and drugs delivery [70]. Importantly, NPs used in these biomedical applications must have a size smaller than $100 \mathrm{~nm}$, high magnetization value, and a narrow particle size distribution $[74,75]$. Biodegradable NPs are being developed as potent drug delivery devices $[76,77]$.

Concerning cancer and cancer diagnosis, majority of the metallic and semiconductor NPs have potential promising contributions in the field of cancer therapy and diagnosis on account of their surface plasmon resonance improved light scattering and absorption [78,79]. Gold NPs, for example, are capable of converting the strong absorbed light into localized heat which can be exploited for the selective laser photo thermal therapy of cancer $[80,81]$. Moreover, the antineoplastic action of NPs is employed to inhibit the growth of tumour $[82,83]$. Silver NPs are another example of NPs used intensively used for their antimicrobial activities in wound healing dressings, catheters and various households' products [84-86]. Potency of NPs as antimicrobial agents can be considered superior to the relatively toxic organic compounds to the biological systems [87]. NPs have various functioning groups which made them capable of killing microbes selectively. TiO2, $\mathrm{ZnO}, \mathrm{BiVO4}, \mathrm{Cu}-$ and Ni-based NPs have been employed for their promising antibacterial activities [88-90].

\section{NPs Applications in Electronics and Printed Electronics}

The significant properties of NPs are reversible assembly, and facile manipulation which facilitate incorporating NPs in electric, electronic or optical devices [91]. Printed electronics development has been attracting increasing attention as they are relatively cheaper and more attractive in comparison with traditional silicon techniques. Contributions of metallic NPS, and ceramics NPs in functional inks used in printed electronics have been expected to flow rapidly as a mass production process for new types of electronic equipment [70]. Exceptional optical, structural, and electrical characteristics of one dimensional semiconductor and metals make them the key structural block for a new generation of electronic, sensors and photonic materials [92].

\section{NPs Applications in Manufacturing and Materials}

Nanotechnology has been known as the next developmental revolution in various industries including food processing and packing, and NPs are already involved in commercially available products. In the field of material science, nano-crystalline materials have promising applications due to their characteristics that deviate from respective bulk material in a size dependent manner. The applications of nanotechnology have been involved in various marketable products such as health fitness products, electronic, and computer related parts, etc. Moreover, many other products are already being mass-produced in the fields of aerospace, microelectronics, and pharmaceutical industries [70]. Those NPs have physicochemical properties that induce unique mechanical, electrical, imaging and optical characteristics that are extremely wanted in some medical, commercial, and ecological applications [93-95]. NPs concentrate on the characterization, designing and engineering of biological and non-biological structures show unique and novel functional properties and having sizes less than $100 \mathrm{~nm}$. On the other hand, some noble metals NPs have promising applications in fields of biosensors and chemical sensors due to their unique Plasmon absorbance features [96].

\section{NPs Applications in Energy and Energy Storage}

Nowadays, scientists are currently shifting their research strategies to generate renewable energies from easily available resources at cheap cost to replace the nonrenewable fossil fuels. NPs are nominated as one of the best candidates for this purpose, thanks to their optical behaviour, large surface area, and catalytic nature. Therefore, NPs are widely used especially in photo catalytic applications in order to generate energy from electrochemical and photo 


\section{Open Access Journal of Microbiology \& Biotechnology}

electrochemical water splitting $[97,98]$. NPs are also used in energy storage applications for energy storage into various forms at nano-scale level, and in nano-generators to convert the mechanical energy into electricity using piezoelectric $[99,100]$.

\section{NPs Applications in the Environment}

Majority of the NPs contributions in industry and household applications leads eventually to the release of them into the environment. Evaluating the risk of accumulation of these materials in the environment needs deep understanding of their impacts on environment through knowing their reactivity, mobility, Eco toxicity and persistency $[100,101]$. The increased NPs concentrations can be observed in groundwater and soil which presents the most significant exposure avenues for assessing environmental risks [102]. On the other hand, how to employ NPs to deal with contaminants depends on NPs properties such as size, morphology, porosity, composition, aggregation and aggregate structure. Due to high surface to mass ratio, natural NPs play key role in the solid/water partitioning of contaminants can be absorbed to the surface of NPs, coprecipitated during the formation of natural NPs or trapped by aggregation of NPs which had contaminants adsorbed to their surface. Environmental NPs applications includes environmentally benign sustainable products (e.g. green chemistry or pollution prevention), remediation of materials contaminated with hazardous substances and sensors for environmental stages [70]. Super paramagnetic iron oxide NPs are potent sorbents capable of removing heavy metals such as mercury, thallium, lead, arsenic, and cadmium from natural water [97]. Additionally, photo degradation by NPs and other nano-materials is commonly employed for this purpose $[103,107]$.

\section{Conclusion}

Nano-materials are increasingly being used in new products and devices with a great impact on different fields especially in biomedicine. Biosynthesis of nano-materials by microorganisms is recently attracting interest as a new, exciting approach towards the development of 'greener' nano-manufacturing compared to traditional chemical and physical approaches. The last ten-year literature was selected, focusing on scientific works where aspects like biosynthesis features, characterization, and applications have been described. Some bacteria and fungi have showed the ability to synthetize unique nanostructures: bacterial nanocellulose, exopolysaccharides, bacterial nanowires, and bio mineralized nano-scale materials (magnetosomes, frustules, and coccoliths). Yeasts and moulds are characterized by extracellular synthesis, beneficial for possible recycle of cell cultures and reduced purification processes of nanomaterial.
Properties of nano-materials vary greatly from macro and micro size materials which play effective role in human health and medicine. Nano medicine aimed to integrate modern nanotechnology with classical molecular tools and biotechnology to develop innovative therapeutics for disease cure and tissue repair, novel drug delivery systems, rapid and ultrasensitive diagnostics tools like biosensors, bio pharmaceutics, surgical aids, implantable biomaterials, etc. Various physical and chemical methods are broadly used for the synthesis of NP. Though these approaches offer higher production rate and better size control over the synthesized NP, they are considered unfavourable due to high capital cost, energy requirements, anaerobic conditions, use of toxic reagents and the generation of hazardous wastes.

Synthesis of NP by biological means offers cheap, nontoxic and eco-friendly alternative to their counter physical and chemical methods. Microbes are found to be tiny nano-factories, and microbial synthesis of NP has merged biotechnology, microbiology and nanotechnology in to a new field of nano-biotechnology. Microbes like bacteria, fungi and yeasts are mostly preferred for NP synthesis, because of their fast growth rate, easy cultivation and their ability to grow at ambient conditions of temperature, $\mathrm{pH}$ and pressure. Microbes offer safe, eco-friendly and economically viable approach of NP synthesis as compared to their chemical alternates, lack of monodispersity, uncontrolled size, and time consuming production process has limited their use on commercial scale.

\section{References}

1. Feynman RP (1960) There's plenty of room at the bottom. Science 23(5): 22-36.

2. Hasan S (2015) A Review on Nanoparticles: Their Synthesis and Types. Res J Recent Sci 4: 9-11.

3. Murray CB, Kagan CR, Bawendi MG (2000) Synthesis and characterisation of monodisperse nanocrystals and close-packed nanocrystal assemblies. Annu Rev Mater Res 30: 545-610.

4. Nowack B, Bucheli TD (2007) Occurrence, behavior and effects of nanoparticles in the environment. Environmental pollution 150(1): 5-22?

5. Ferrari M (2005) Cancer nanotechnology: opportunities and challenges. Nat Rev Cancer 5(3): 161-171.

6. Cho EJ, Holback H, Liu K, Abouelmagd SA, Park J, et al. (2013) Nanoparticle characterization: State of the art, challenges, and emerging technologies. Mol Pharm 10(6): 2093-2110. 


\section{Open Access Journal of Microbiology \& Biotechnology}

7. Machado S, Pacheco JG, Nouws HPA, Albergaria JT, Delerue-Matos C (2015) Characterization of green zero-valent iron nanoparticles produced with tree leaf extracts. Sci Total Environ 533: 76-81.

8. Chen H, Roco MC, Li X, Lin Y (2008) Trends in nanotechnology patents. Nat Nanotechnol 3: 123-125.

9. Li Y, Duan X, Qian Y, Yang L, Liao H (1999) Nanocrystalline silver particles: synthesis, agglomeration, and sputtering induced by electron beam. J Colloid Interface Sci 209(2): 347-349.

10. Choi Y, Nan-Hui Ho, Ching-Hsuan T (2007) Sensing phosphatase activity by using gold nanoparticles. Angew Chem Int Ed Engl 46(5): 707-709.

11. Yoosaf K, Ipe BI, Suresh CH, Thomas KG (2007) In situ synthesis of metal nanoparticles and selective naked-eye detection of lead ions from aqueous media. J Phys Chem 111: 12839-12847.

12. Hutter E, Fendler JH (2004) Exploitation of localized surface plasmon resonance. Adv Mater 16(19): 16851706.

13. Sun S, Murray CB, Weller D, Folks L, Moser A (2000) Monodisperse $\mathrm{FePt}$ nanoparticles and ferromagnetic FePt nanocrystal superlattices. Science 287(5460): 1989-1992.

14. Vilchis-Nestor AR, Sanchez-Mendieta V, Camacho-Lopez M, Gomez-Espinosa RM, Camacho-Lopez MA, et al. (2008) Solvent less synthesis and optical properties of $\mathrm{Au}$ and $\mathrm{Ag}$ nanoparticles using Camellia sinensis extract. Mater Lett 62(17-18): 3103-3105.

15. Lee HJ, Yeo SY, Jeong SH (2003) Antibacterial effect of nanosized silver colloidal solution on textile fabrics. J Mater Sci 38: 2199-2204.

16. Zhang J, Chen P, Sun C, Hu X (2004) Sonochemical synthesis of colloidal silver catalysts for reduction of complexing silver in DTR system. Appl Catal A Gen 266(1): 49-54.

17. Chimentão RJ, Kirm I, Medina F, Rodríguez X, Cesteros $Y$ (2004) Different morphologies of silver nanoparticles as catalysts for the selective oxidation of styrene in the gas phase. Chem Commun (Camb) 846-847.

18. He B, Tan J, Liew K, Liu H (2004) Synthesis of sizecontrolled Ag nanoparticles. J Mol Catal A 221(1-2): 121126.

19. Marsalek R (2014) Particle Size and Zeta Potential of ZnO. APCBEE Procedia 9: 13-17.
20. Sharma V, Rao LJ (2014) An overview on chemical composition, bioactivity and processing of leaves of Cinnamomum tamala. Crit Rev Food Sci Nutr 54(4): 433448.

21. Bzdek BR, Zordan C, Iii G, Johnston MV (2011) Nanoparticle Chemical Composition During New Particle Formation. Aerosol Science and Technology 45(8): 10411048.

22. Hodoroaba V, Rades S, Unger WE (2014) Inspection of morphology and elemental imaging of single nanoparticles by high- resolution SEM / EDX in transmission mode. Surface and interface analysis 46(1011): $945-948$.

23. Yano F, Hiraoka A, Itoga T, Kojima H, Kanehori $\mathrm{K}$, et al. (1996) Influence of ionimplantation on native oxidation of $\mathrm{Si}$ in a clean-room atmosphere. Appl Surf Sci 100-101: 138-142.

24. Shankar SS, Rai A, Ahmad A, Sastry M (2004) Biosynthesis of silver and gold nanoparticles from extracts of different parts of the Geranium plant. Applications in Nanotechnology 1: 69-77.

25. Chandran SP, Chaudhary M, Pasricha R, Ahmad A, Sastry $M$ (2006) Synthesis of gold nanotriangles and silver nanoparticles using Aloe vera plant extract. Biotechnol Prog 22(2): 577-583.

26. Huang J, Li Q, Sun D, Lu Y, Su Y, et al. (2007) Biosynthesis of silver and gold nanoparticles by novel sundried Cinnamomum camphora leaf. Nanotechnology 18(10): 104-105.

27. Patil CD, Patil SV, Borase HP, Salunke BK, Salunkhe RB (2012) Larvicidal avtivity of silver nanoparticles synthesised using Plumeria rubra plant latex against Aedes aegypti and Anopheles stephensi. Parasitol Res 110(5): 1815-1822.

28. Singh AK, Talat M, Singh DP, Srivastava ON (2010) Biosynthesis of gold and silver nanoparticles by natural precursor clove and their functionalization with amine group. J Nanopart Res 12(5): 1667-1675.

29. Christensen L, Vivekanandhan S, Misra M, Mohanty A (2011) Biosynthesis of silver nanoparticles using murraya koenigii (curry leaf): An investigation on the effect of broth concentration in reduction mechanism and particle size. Adv Mat Lett 2(6): 429-434.

30. Vankar PS, Bajpai D (2010) Preparation of gold nanoparticles from Mirabilis jalapa flowers. Indian J Biochem Biophys 47(3): 157-160. 


\section{Open Access Journal of Microbiology \& Biotechnology}

31. Sunkar S, Nachiyar CV (2012) Microbial synthesis and characterization of silver nanoparticles using the endophytic bacterium Bacillus cereus: a novel source in the benign synthesis. Global Journal of Medical Research 12(2): 43-49.

32. Slawson RM, Lohmeier-Vogel EM, Lee H, Trevors JT (1994) Silver resistance in Pseudomonas stutzeri. Biometals 7(1): 30-40.

33. Sharma N, Pinnaka AK, Raje M, Fnu A, Bhattacharyya MS, et al. (2012) Exploitation of marine bacteria for production of gold nanoparticles. Microb Cell Fact 11: 86.

34. Prasad K, Jha AK, Kulkarni AR (2007) Lactobacillus assisted synthesis of titanium nanoparticles. Nanoscale Res Lett 2: 248-250.

35. Gade AK, Bonde P, Ingle AP, Marcato PD, Durän N, et al. (2008) Exploitation of Aspergillus niger for synthesis of silver nanoparticles. Journal of Biobased Materials and Bioenergy 2(3): 243-247.

36. Binupriya AR, Sathishkumar M, Yun SI (2010) Mycocrystallization of silver ions to nanosized particles by live and dead cell filtrates of Aspergillus oryzae var. viridis and its bactericidal activity toward Staphylococcus aureus KCCM 12256. Ind Eng Chem Res 49(2): 852-858.

37. Avinash I, Mahendra R, Aniket G, Manisha B (2009) Fusarium solani: A novel biological agent for the extracellular synthesis of silver nanoparticles. J Nanopart Res 11(8): 2079-2085.

38. Nithya R, Ragunathan R (2009) Synthesis of silver nanoparticles using Pleurotus sajor caju and its antimicrobial study. Digest Journal of Nanomaterials and Biostructures 4(4): 623-629.

39. Thakkar KN, Mhatre SS, Parikh RY (2010) Biological synthesis of metallic nanoparticles. Nanomedicine 6(2): 257-262.

40. Ahmad A, Mukherjee P, Senapati S, Mandal D, Khan MI, et al. (2003) Extracellular biosynthesis of silver nanoparticles using the fungus Fusarium oxysporum. Colloids and Surfaces B: Biointerfaces 28(4): 313-318.

41. Birla SS, Tiwari VV, Gade AK, Ingle AP, Yadav AP, et al. (2009) Fabrication of silver nanoparticles by Phoma glomerata and its combined effect against Escherichia coli, Pseudomonas aeruginosa and Staphylococcus aureus. Lett Appl Microbiol 48(2): 173-179.

42. Sadowski Z, Maliszewska IH, Grochowalska B, Polowczyk I, Kozlecki T (2008) Synthesis of silver nanoparticles using microorganisms. Materials Science- Poland 26(2): 419-424.

43. Kowshik M, Ashtaputre S, Kharrazi S, Vogel W, Urban J, et al. (2002) Extracellular synthesis of silver nanoparticles by a silver-tolerant yeast strain. MKY3. Nanotechnology 14(1): 95-100.

44. Dameron CT, Reese RN, Mehra RK, Kortan AR, Carroll PJ, et al. (1989) Biosynthesis of cadmium sulphide quantum semiconductor crystallites. Nature 338(6216): 596-597.

45. Mourato A, Gadanho M, Lino AR, Tenreiro R (2011) Biosynthesis of crystalline silver and gold nanoparticles by extremophilic yeasts. Bioinorg Chem Appl 2011: 546074 .

46. Seshadri S, Saranya K, Kowshik M (2011) Green synthesis of lead sulfide nanoparticles by the lead resistant marine yeast, Rhodosporidium diobovatum. Biotechnol Prog 27(5): 1464-1469.

47. Kalpana Devi V, Sumathi R, Varalakshmi P (1994) Evaluation of the antidotal effect of DL-?-lipoic acid against mercuric chloride induced acute renal dysfunction. Med Sci Res 22: 859-862.

48. Pala R, Pathipati UR, Bojja S (2010) Qualitative assessment of silver and gold nanoparticle synthesis in various plants: A photobiological approach. J Nanopart Res 12: 1711-1721.

49. Babu GMM, Gunasekaran P (2009) Production and structural characterization of crystalline silver nanoparticles from Bacillus cereus isolate. Colloids Surf B Biointerfaces 74(1): 191-195.

50. Jain D, Kachhwaha S, Jain R, Srivastava G, Kothari SL (2010) Novel microbial route to synthesize silver nanoparticles using spore crystal mixture of Bacillus thuringiensis. Indian J Exp Biol 48(11): 1152-1156.

51. Gurunathan S, Kalishwaralal K, Vaidyanathan R, Venkataraman D, Pandian SR, et al. (2009) Biosynthesis, purification and characterization of silver nanoparticles using Escherichia coli. Colloids Surf B Biointerfaces 74(1): 328-335.

52. Sweeney RY, Mao C, Gao X, Burt JL, Belcher AM, et al. (2004) Bacterial biosynthesis of cadmium sulfide nanocrystals. Chem Biol 11(11): 1553-1559.

53. Sintubin L, De Windt W, Dick J, Mast J, van der Ha D, et al. (2009) Lactic acid bacteria as reducing and capping agent for the fast and efficient production of silver nanoparticles. Appl Microbiol Biotechnol 84(4): 741749. 


\section{Open Access Journal of Microbiology \& Biotechnology}

54. Klaus T, Joerger R, Olsson E, Granqvist CG (1999) Silverbased crystalline nanoparticles, microbially fabricated. Proc Natl Acad Sci USA 96(24): 13611-13614.

55. Zhang H, Li Q Lu Y, Sun D, Lin X, et al. (2005) Biosorption and bioreduction of diamine silver complex by Corynebacterium. J Chem Technol Biotechnol 80(3): 285-290.

56. Nanda A, Saravanan M (2009) Biosynthesis of silver nanoparticles from Staphylococcus aureus and its antimicrobial activity against MRSA and MRSE. Nanomedicine 5(4): 452-456.

57. Duran N, Marcato PD, De Souza GIH, Alves OL, Esposito E (2007) Antibacterial effect of silver nanoparticles produced by fungal process on textile fabrics and their effluent treatment. J Biomed Nanotechnol 3: 203-208.

58. Nithya R, Ragunathan R (2009) Synthesis of silver nanoparticles using Pleurotus sajor caju and its antimicrobial study. Digest Journal of Nanomaterials and Biostructures 4(4): 623-629.

59. Fesharakil PJ, NazariI P, ShakibaieI M, RezaieII S, Banoee M, et al. (2010) Biosynthesis of selenium nanoparticles using Klebsiella pneumoniae and their recovery by a simple sterilization process. Braz J Microbiol 41(2): 461466.

60. Tiwari DK, Behari J, Sen P (2008) Application of Nanoparticles in Waste Water Treatment. World Applied Science Journal 3: 417-433.

61. Salavati-niasari M, Davar F, Mir N (2008) Synthesis and characterization of metallic copper nanoparticles via thermal decomposition Polyhedron 27(17): 3514-3518.

62. Tai CY, Tai C, Chang M, Liu H (2007) Synthesis of Magnesium Hydroxide and Oxide Nanoparticles Using a Spinning Disk Reactor. Ind Eng Chem Res, pp: 55365541.

63. Bhaviripudi S, Mile E, Steiner SA, Zare AT, Dresselhaus MS, et al. (2007) CVD Synthesis of Single-Walled Carbon Nanotubes from Gold Nanoparticle Catalysts. J Am Chem Soc 29(6): 1516-1517.

64. Martis E, Badve R, Degwekar M (2012) Nanotechnology based devices and applications in medicine: An overview. Chronicles of young Scientists 3(1): 1-10.

65. Emeje MO, Obidike IC, Akpabio EI, Ofoefule SI (2012) Nanotechnology in drug delivery. Recent advances in novel drug carrier systems 69-106.

66. Loureiro A, Azoia NG, Gomes AC, Cavaco-Paulo A (2016)
Albumin-based nanodevices as drug carriers. Curr pharm Des 22(10): 1371-1390.

67. Khan I, Saeed K, Khan I (2019) Nanoparticles: Properties, applications and toxicities. Arabian journal of chemistry 12(7): 908-931.

68. El-Sheikh SM, Khairy MH, Osama E, Metwally MM, Galal AA (2021) Nanotechnology improves the therapeutic efficacy of gemcitabine against a human hepatocellular carcinoma cell line and minimizes its in vivo side effects. Naunyn-Schmiedeberg's Arch Pharmacol 394(4): 631-643.

69. Blyakhman FA, Safronov AP, Zubarev AY, Shklyar TF, Makeyev OG, et al. (2017) Polyacrylamide ferrogels with embedded maghemite nanoparticles for biomedical engineering. Results in physics 7: 3624-3633.

70. Yew YP, Shameli K, Miyake M, Khairudin NB, Mohamad SE, et al. (2020) Green biosynthesis of superparamagnetic magnetite Fe304 nanoparticles and biomedical applications in targeted anticancer drug delivery system: A review. Arabian Journal of Chemistry 13(1): 2287-2308.

71. Laurent S, Forge D, Port M, Roch A, Robic C, et al. (2008) Magnetic iron oxide nanoparticles: synthesis, stabilization, vectorization, physicochemical characterizations, and biological applications. Chem Rev 108(6): 2064-2110.

72. Elrefai AL, Yoshida T, Enpuku K (2019) Magnetic parameters evaluation of magnetic nanoparticles for use in biomedical applications. Journal of Magnetism and Magnetic Materials 474: 522-527.

73. Kumari A, Yadav SK, Yadav SC (2010) Biodegradable polymeric nanoparticles based drug delivery systems. Colloids Surfs B Biointerfaces 75(1): 1-18.

74. Saito E, Kuo R, Pearson RM, Gohel N, Cheung B, et al. (2019) Designing drug-free biodegradable nanoparticles to modulate inflammatory monocytes and neutrophils for ameliorating inflammation. J Control Release 300: 185-196.

75. Cordani M, Somoza Á (2019) Targeting autophagy using metallic nanoparticles: a promising strategy for cancer treatment. Cell Mol Life Sci 76(7): 1215-1242.

76. Zhang D, Ma XL, Gu Y, Huang H, Zhang GW (2020) Green Synthesis of Metallic Nanoparticles and Their Potential Applications to Treat Cancer. Front Chem 8: 799.

77. Huang X, El-Sayed MA (2010) Gold nanoparticles: Optical properties and implementations in cancer diagnosis and photothermal therapy. Journal of Advanced 


\section{Open Access Journal of Microbiology \& Biotechnology}

Research 1(1): 13-28.

78. Singh P, Pandit S, Mokkapati VR, Garg A, Ravikumar $\mathrm{V}$, et al. (2018) Gold nanoparticles in diagnostics and therapeutics for human cancer. Int J Mol Sci 19(7): 1979.

79. Liang JJ, Zhou YY, Wu J, Ding Y (2014) Gold nanoparticlebased drug delivery platform for antineoplastic chemotherapy. Curr Drug metab 15(6): 620-631.

80. Khatua A, Prasad A, Priyadarshini E, Patel AK, Naik A, et al. (2020) Emerging antineoplastic plant-based gold nanoparticle synthesis: a mechanistic exploration of their anticancer activity toward cervical cancer cells. Journal of Cluster Science 31(6): 1329-1340.

81. Roe D, Karandikar B, Bonn-Savage N, Gibbins B, Roullet JB (2008) Antimicrobial surface functionalization of plastic catheters by silver nanoparticles. J Antimicrob Chemother 61(4): 869-876.

82. Maneerung T, Tokura S, Rujiravanit R (2008) Impregnation of silver nanoparticles into bacterial cellulose for antimicrobial wound dressing. Carbohydrate polymers $72(1)$ : 43-51.

83. Lewisoscar F, Nithya C, Vismaya S, Arunkumar M, Pugazhendhi A, et al. (2021) In vitro analysis of green fabricated silver nanoparticles (AgNPs) against Pseudomonas aeruginosa PA14 biofilm formation, their application on urinary catheter. Progress in Organic Coatings 151: 106058.

84. Hajipour MJ, Fromm KM, Ashkarran AA, de Aberasturi DJ, de Larramendi IR, et al. (2012) Antibacterial properties of nanoparticles. Trends Biotechnol 30(10): 499-511.

85. Espitia PJ, Soares ND, dos Reis Coimbra JS, de Andrade NJ, Cruz RS, et al. (2012) Zinc oxide nanoparticles: synthesis, antimicrobial activity and food packaging applications. Food and bioprocess technology 5(5): 1447-1464.

86. Bogdanović $\mathrm{U}$, Lazić V, Vodnik V, Budimir M, Marković Z, et al. (2014) Copper nanoparticles with high antimicrobial activity. Materials Letters 128(1): 75-78.

87. Basavegowda N, Baek KH (2021) Multimetallic Nanoparticles as Alternative Antimicrobial Agents: Challenges and Perspectives. Molecules 26(4): 912.

88. O'Brien S, Brus L, Murray CB (2001) Synthesis of monodisperse nanoparticles of barium titanate: toward a generalized strategy of oxide nanoparticle synthesis. J Am Chem Soc 123(48): 12085-12086.

89. Shaalan M, Saleh M, El-Mahdy M, El-Matbouli M (2016)
Recent progress in applications of nanoparticles in fish medicine: A review. Nanomedicine 12(3): 701-710.

90. Junghanns JU, Müller RH (2008) Nanocrystal technology, drug delivery and clinical applications. Int J Nanomedicine 3(3): 295-309.

91. Dong H, Wen B, Melnik R (2014) Relative importance of grain boundaries and size effects in thermal conductivity of nanocrystalline materials. Scientific reports 4(1): 1-5.

92. Hartley CL, Kessler ML, Dempsey JL (2021) MolecularLevel Insight into Semiconductor Nanocrystal Surfaces. J Am Chem Soc 143(3): 1251-1266.

93. Unser S, Bruzas I, He J, Sagle L (2015) Localized surface plasmon resonance biosensing: current challenges and approaches. Sensors(Basel) 15(7): 15684-15716.

94. Mueller NC, Nowack B (2008) Exposure modeling of engineered nanoparticles in the environment. Environ Sci Technol 42(12): 4447-4453.

95. Ning F, Shao M, Xu S, Fu Y, Zhang R, et al. (2016) TiO 2/ graphene/NiFe-layered double hydroxide nanorod array photoanodes for efficient photoelectrochemical water splitting. Energy \& Environmental Science 9(8): 26332643.

96. Sagadevan S (2015) A review on role of nanofluids for solar energy applications. American Journal of Nano Research and Applications 3(3): 53-61.

97. Sun M, Dong H, Dougherty AW, Lu Q Peng D, et al. (2019) Nanophotonic energy storage in upconversion nanoparticles. Nano Energy 56: 473-481.

98. Bundschuh M, Filser J, Lüderwald S, McKee MS, Metreveli G, et al. (2018) Nanoparticles in the environment: where do we come from, where do we go to? Environ Sci Eur 30(1): 06.

99. Tortella GR, Rubilar 0, Durán N, Diez MC, Martínez M, et al. (2020) Silver nanoparticles: Toxicity in model organisms as an overview of its hazard for human health and the environment. J Hazard Mat 390: 121974.

100. Golobic M, Jemec A, Drobne D, Romih T, Kasemets $\mathrm{K}$, et al. (2012) Upon exposure to $\mathrm{Cu}$ nanoparticles, accumulation of copper in the isopod Porcellio scaber is due to the dissolved $\mathrm{Cu}$ ions inside the digestive tract. Environ Sci Technol 46(21): 12112-12119.

101. Akhavan O, Abdolahad M, Esfandiar A, Mohatashamifar M (2010) Photodegradation of graphene oxide sheets by TiO2 nanoparticles after a photocatalytic reduction. J Phys Chem C 114(30): 12955- 


\section{Open Access Journal of Microbiology \& Biotechnology}

12959.

102. Moradnia F, Fardood ST, Ramazani A, Gupta VK (2020) Green synthesis of recyclable MgFeCrO4 spinel nanoparticles for rapid photodegradation of direct black 122 dye. Journal of Photochemistry and Photobiology A: Chemistry 392(1): 112433.

103. Grasso G, Zane D, Dragone R (2019) Microbial nanotechnology: Challenges and prospects for green biocatalytic synthesis of Nano scale materials for sensoristic and biomedical applications. Nanomaterials (Basel) 10(1): 11.

104. Sengül H, Theis T, Ghosh S (2008) Toward sustainable nanoproducts: An overview of nanomanufacturing methods. J Ind Ecol 12(3): 329-359.

105. Fang FZ, Zhang X, Gao W, Guo Y, Byrne G, et al. (2017) Nanomanufacturing-Perspective and applications. CIRP Ann 66(2): 683-705.

106. Yuan C, Zhang T (2013) Environmental Implications of Nano-manufacturing. In Green Manufacturing, Dornfeld D (Eds.), Springer: Boston, MA, USA.

107. Fariq A, Khan T, Yasmin A (2017) Microbial synthesis of NP and their potential applications in biomedicine. Journal of Applied Biomedicine 15(4): 241248.

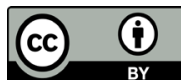

